Maternal Knowledge as a Mediator of the Relation Between Maternal Psychological Control and Altruistic Prosocial, Instrumental Prosocial, and Antisocial Behavior

Author(s): Athanasios Mouratidis, Melike Sayil, Asiye Kumru, Bilge Selcuk and Bart Soenens

Source: Merrill-Palmer Quarterly, Vol. 65, No. 2 (April 2019), pp. 207-231

Published by: Wayne State University Press

Stable URL: https://www.jstor.org/stable/10.13110/merrpalmquar1982.65.2.0207

JSTOR is a not-for-profit service that helps scholars, researchers, and students discover, use, and build upon a wide range of content in a trusted digital archive. We use information technology and tools to increase productivity and facilitate new forms of scholarship. For more information about JSTOR, please contact support@jstor.org.

Your use of the JSTOR archive indicates your acceptance of the Terms \& Conditions of Use, available at https://about.jstor.org/terms 


\title{
Maternal Knowledge as a Mediator of the Relation Between Maternal Psychological Control and Altruistic Prosocial, Instrumental Prosocial, and Antisocial Behavior
}

\author{
Athanasios Mouratidis TED University \\ Melike Sayil TED University \\ Asiye Kumru Özye University \\ Bilge Selcuk Koç University \\ Bart Soenens Ghent University
}

\begin{abstract}
Past research has shown that, while psychological control increases the risk for adolescents' antisocial behavior, maternal knowledge of adolescents' activities decreases this risk. Yet, research is somewhat inconclusive about the role of psychologically controlling parenting in parental knowledge. Also, the role of both predictors in prosocial behavior remains largely unknown. In this 1-year, multiinformant, prospective study, we investigated these issues by recruiting a sample of Turkish early adolescents $\left(N=229, M_{\text {age }}=11.89\right.$ years, $S D=0.32,47.0 \%$ boys) and their mothers. After controlling for baseline adolescent-reported maternal knowledge, we found mother-reported psychological control to negatively predict adolescent-reported maternal knowledge 1 year later. In turn, maternal knowledge related negatively to antisocial behavior and positively to altruistic prosocial behavior (but not to instrumental prosocial behavior). These findings highlight the key role that maternal psychological control and knowledge can have in adolescents' social functioning.
\end{abstract}

Athanasios Mouratidis, Melike Sayil, Asiye Kumru, Bilge Selcuk, and Bart Soenens, Department of Psychology.

This study was supported by a research grant from the Scientific and Technological Research Council of Turkey-TUBITAK (SOBAG 104K068) to Asiye Kumru.

Address correspondence to Athanasios A. Mouratidis, Department of Psychology, TED University, 48 Ziya Gokalp Street, Ankara 06420, Turkey. Phone: +30 231551 1000. E-mail: athanasiosmouratidis@tedu.edu.tr.

Merrill-Palmer Quarterly, April 2019, Vol. 65, No. 2, pp. 207-231. doi: 10.13110/merrpalmquar 1982.65.2.0207 Copyright (C) 2019 by Wayne State University Press, Detroit, MI 48201. 
Particularly in adolescence, it is important for parents to know about a child's activities, friendships, and whereabouts (Crouter \& Head, 2002; Dishion \& McMahon, 1998). Through such knowledge, parents can, among other things, prevent their children from deviant peer affiliations (Soenens, Vansteenkiste, Luyckx, \& Goossens, 2006) and aggressive behaviors (Barber, Stolz, Olsen, Collins, \& Burchinal, 2005). A vast amount of research has indeed shown that parental knowledge relates to less problem behavior, such as disobedience to parents, school misconduct, and aggressive behavior (Ary et al., 1999; Galambos, Barker, \& Almeida, 2003; Veronneau \& Dishion, 2010).

Given this massive evidence for the protective role of parental knowledge in adolescents' behavior, research also addressed developmental antecedents of parental knowledge, thereby focusing particularly on the role of parenting. Research has mainly indicated that parents obtain higher levels of knowledge when the parent-adolescent relationship is characterized by warmth, closeness, and support (e.g., Fletcher, Steinberg, \& Williams-Wheeler, 2004; Soenens et al., 2006). While the role of parental warmth and closeness in parental knowledge is clear and well established, research about the role of other parenting dimensions is scarcer. In this regard, only a limited number of studies examined the role of psychologically controlling parenting, which refers to parenting that is intrusive, disrespectful, and manipulative (Barber, 1996). Such parenting is predictive of various forms of maladjustment among adolescents, including internalizing distress and externalizing problem behaviors (Barber, 1996; Pettit, Laird, Dodge, Bates, \& Criss, 2001). While there are reasons to assume that psychologically controlling parents gain less knowledge about their adolescent's whereabouts, with such reduced knowledge in turn creating risk for problem behaviors, only few studies to date formally addressed the possibility that parental knowledge plays an intervening role in associations between psychologically controlling parenting and antisocial behavior. Apart from testing this mediation sequence, our additional goal was to contribute to the literature by examining associations of maternal psychological control and knowledge not only with aggressive behavior but also with types of adolescent prosocial behavior. This is important because certain types of prosocial behavior, such as instrumental prosocial behavior, where a person helps others in return for some future benefits, may be orthogonal to aggressive behavior (Boxer, Tisak, \& Goldstein, 2004). In that way, we aimed to examine whether maternal knowledge is linked with adolescents' integration of societal values of not only abstaining from aggressive behaviors but also of endorsing prosocial, altruistic ones. 
Parental Psychological Control and Parental Knowledge

Parental psychological control refers to parents' behaviors and practices that intrude on the emotional and psychological private space of the adolescent (Barber et al., 2005). Such parental behaviors and practices include constraining verbal expressions, invalidating feelings, love withdrawal, guilt induction, erratic emotional behavior, and disrespect of the adolescent's identity (Barber, Xia, Olsen, McNeely, \& Bose, 2012). Parental psychological control has been linked with a host of negative outcomes, including adolescents' depressive symptoms (Barber, 1996), relational aggression (Kuppens, Grietens, Onghena, \& Michiels, 2009; Soenens, Vansteenkiste, Goossens, Duriez, \& Niemiec, 2008), and aggressive behaviors (Galambos et al., 2003; Mabbe, Soenens, Vansteenkiste, \& Van Leeuwen, 2016).

One of the mechanisms through which psychological control may relate to these adverse developmental outcomes is reduced parental knowledge. Psychological control is expected to relate to lower parental knowledge because adolescents are less likely to disclose information to parents when they anticipate that parents would respond to undesirable information with psychologically controlling behavior (e.g., guilt induction and love withdrawal). In response to psychologically controlling parenting, adolescents may even defy parents' intrusiveness, thereby actively concealing information and keeping secrets (Van Petegem, Soenens, Vansteenkiste, \& Beyers, 2015). Thus, psychological control is expected to relate to lower parental knowledge, with such decreased knowledge, in turn, forecasting greater risk for problem behaviors, as has been demonstrated in many previous studies (Kerr \& Stattin, 2000; Laird, Pettit, Dodge, \& Bates, 2003). When parents are less aware of adolescents' whereabouts, they are less able to intervene appropriately in adolescents' behavior and prevent adolescents from harmful behaviors (e.g., by setting rules and by warning adolescents about the consequences of harmful behavior).

Relatively few studies addressed associations between psychologically controlling parenting and parental knowledge. Moreover, these studies have shown that associations are somewhat inconclusive (Pettit et al., 2001; Smetana, Metzger, Gettman, \& Campione-Barr, 2006; Smetana \& Rote, 2015; Soenens et al., 2006; Stattin \& Kerr, 2000). Although most research has demonstrated the theoretically anticipated associations between parental psychological control and lower parental knowledge (e.g., Hawk et al., 2013; Lansford et al., 2014; Tilton-Weaver et al., 2010), a few found no relation between psychological control and parental knowledge (e.g., Horton \& Tritch, 2014; Smetana \& Daddis, 2002; Smetana \& Rote, 2015). Further, even fewer studies addressed the possibility that low parental knowledge plays an 
intervening role in associations between parental psychological control and adolescent problem behaviors. An exception is a study with Belgian adolescents (Soenens et al., 2006) that demonstrates indirect associations between parental psychological control and adolescent delinquency through reduced adolescent disclosure and subsequent low parental knowledge. Clearly, there is a need for additional studies in other countries and cultures to explicitly test the presumed intervening role of parental knowledge.

Thus, in the current study with Turkish adolescents, we aimed to provide a rigorous test of the relation between maternal psychological control and maternal knowledge. Specifically, we aimed to examine this relation across different informants (i.e., adolescents and mothers) and after controlling for baseline levels of maternal knowledge. In turn, we considered maternal knowledge a predictor of adolescent aggressive behavior, and, as such, we modeled it as an intervening variable linking psychologically controlling parenting and adolescent aggression.

\section{Parental Knowledge and Prosocial Functioning}

Another way in which we aimed to contribute to the literature was by examining associations of maternal psychological control and knowledge not only with aggressive behavior but also with prosocial behavior. Prior research has indicated that maternal knowledge can constrain children's misconduct problems, most likely because such knowledge provides a basis for mothers to discuss the risks and consequences of problematic behavior. Such motheradolescent conversations about the hazards of risky behaviors may help adolescents to better realize why they should refrain from misbehaviors.

Most previous research, however, has focused mainly on the relation between maternal knowledge and adolescent misconduct (e.g., Barber et al., 2005; Kerr \& Stattin, 2000), whereas less attention has been paid to the relations between parental knowledge and positive social outcomes such as prosocial behavior (Elgar, Mills, McGrath, Waschbusch, \& Brownridge, 2007) and the high quality of friendships (Gaertner, Fite, \& Colder, 2010). This is unfortunate because parental knowledge may serve not only as a basis for parent-adolescent conversations about why problem behavior should be avoided but also as a basis for discussions that encourage prosocial behaviors. Further, an examination of the role of psychologically controlling parenting and parental knowledge in prosocial behavior is important because research has shown that certain types of prosocial behavior (e.g., instrumental helping) and aggressive behavior are to some extent orthogonal (Boxer et al., 2004). An absence of aggressive behavior cannot be equated with the presence of prosocial behavior, or at least with certain types of it. Accordingly, developmental predictors (such as 
parental knowledge) that decrease the risk of aggressive behavior do not necessarily foster prosocial behavior. Thus, it remains to be examined whether psychologically controlling parenting and parental knowledge predict not only aggressive behavior but also prosocial behavior.

Moreover, the few studies that examined parental knowledge in relation to prosocial behavior have treated prosocial behavior in a rather undifferentiated way. This gap in the literature deserves further investigation because several developmental and social motivation theories (e.g., Batson, Ahmad, Powell, $\&$ Stocks, 2005) have proposed important distinctions between types of prosocial behavior. These distinctions can further inform us about role of parental knowledge in adolescents' prosocial development. Batson and Shaw (1991), for instance, distinguished between two broad categories of prosocial behavior with markedly different dynamics: altruistic prosocial behavior and egoistic, or instrumental, prosocial behavior. Whereas altruistic prosocial behavior is rooted in a genuine empathic response to other people and is aimed at helping a person in need, egoistic prosocial behavior is rooted in more self-centered motives (i.e., gaining rewards or avoiding personal distress; see Weinstein, DeHaan, \& Ryan, 2010). Along similar lines, Boxer et al. (2004) have proposed that behaving prosocial for instrumental reasons (termed proactive prosocial behavior) should not be considered as equivalent of true altruistic behavior (i.e., acting in a prosocial way without expecting anything in return). Boxer et al. (2004) have empirically differentiated instrumental prosocial behavior from altruistic prosocial behavior and showed that, unlike altruistic prosocial, instrumental prosocial behavior was related positively to aggressive behaviors and normative beliefs favoring the use of aggression. Another study similarly demonstrated that instrumental prosocial behavior was positively linked with both relational and physical aggression (Culotta \& Goldstein, 2008). Although taking a somewhat different approach, Carlo et al. (2014) have indicated, as well (see also McGinley \& Carlo, 2007), that altruistic behaviors were negatively related to aggressive and delinquent behaviors, whereas this was not the case for public prosocial behaviors (which have been conceptualized as prosocial behaviors that are enacted in the presence of others). In sum, an extended line of research has indicated that altruistic prosocial behavior relates to better adjustment than does instrumental prosocial behavior. However, the relation of parental knowledge to both types of prosocial behavior remains unclear.

Data regarding this relation can help us further uncover the potential developmental benefits of parental knowledge. If parental knowledge relates negatively to aggressive behavior and positively to altruistic prosocial behavior (but not to instrumental prosocial behavior), this would imply that maternal knowledge may be more than needed because it can serve as a means not only to prevent adolescents from misbehaving but also to promote true altruistic prosocial behavior. 
The Present Study

In this prospective study with Turkish adolescents, we aimed to investigate to what extent maternal psychological control predicts changes in maternal knowledge 1 year later and whether such maternal knowledge, in turn, relates to adolescents' self-reported prosocial and aggressive behavior. We aimed to build on prior research in four important ways. First, we examined the intervening role of maternal knowledge in how parental psychological control is related to aspects of adolescents' behavior. Second, we focused not only on one of the darker sides of adolescents' behavior, that of aggressive behavior, but also on a brighter one, that of prosocial behavior. Third, we aimed to differentiate prosocial behavior into an altruistic component and an instrumental component (Batson et al., 2005) and then examine how they both relate to maternal psychological control and maternal knowledge. Fourth, we tried to cross-check the hypothesized relations by using both the mothers and the adolescents as informants. We were particularly interested in testing to what extent the psychological control that a mother admits that she exerts over her child (i.e., mother-reported psychological control) is predictive of the maternal knowledge reported by the adolescent. While, in principle, we could also test such a model with mother-reported knowledge as an outcome (thereby using adolescent-reported psychological control as a predictor), ultimately adolescents know best whether their mother really has accurate information about their own activities (Smetana, 2008). As such, it was deemed most important to test a model with adolescent-reported knowledge as the central intervening variable. Fifth, when examining the relation between psychological control and maternal knowledge, we controlled for baseline levels of maternal knowledge. This enabled us to test more conservatively the role of psychological control in predicting subsequent changes in maternal knowledge.

The hypotheses are displayed graphically in Figure 1. We expected psychological control to negatively predict subsequent mothers' knowledgeof adolescents' activities, friendships, and whereabouts, even after we controlled for baseline maternal knowledge (Hypothesis 1). We expected this relation to hold even when we rely on mother-reported psychological control and adolescents' reports about how many aspects of their own activities their mothers know. With respect to the links between maternal knowledge and aggressive and prosocial behavior, we assumed that maternal knowledge would relate negatively to aggressive behavior (Hypothesis 2a) and positively to altruistic prosocial behavior (Hypothesis $2 b$ ). We did not expect an association between maternal knowledge and instrumental prosocial behavior (Hypothesis 2c) as the latter is presumed to reflect a means-to-an-end strategic behavior rather than true prosocial behavior. 


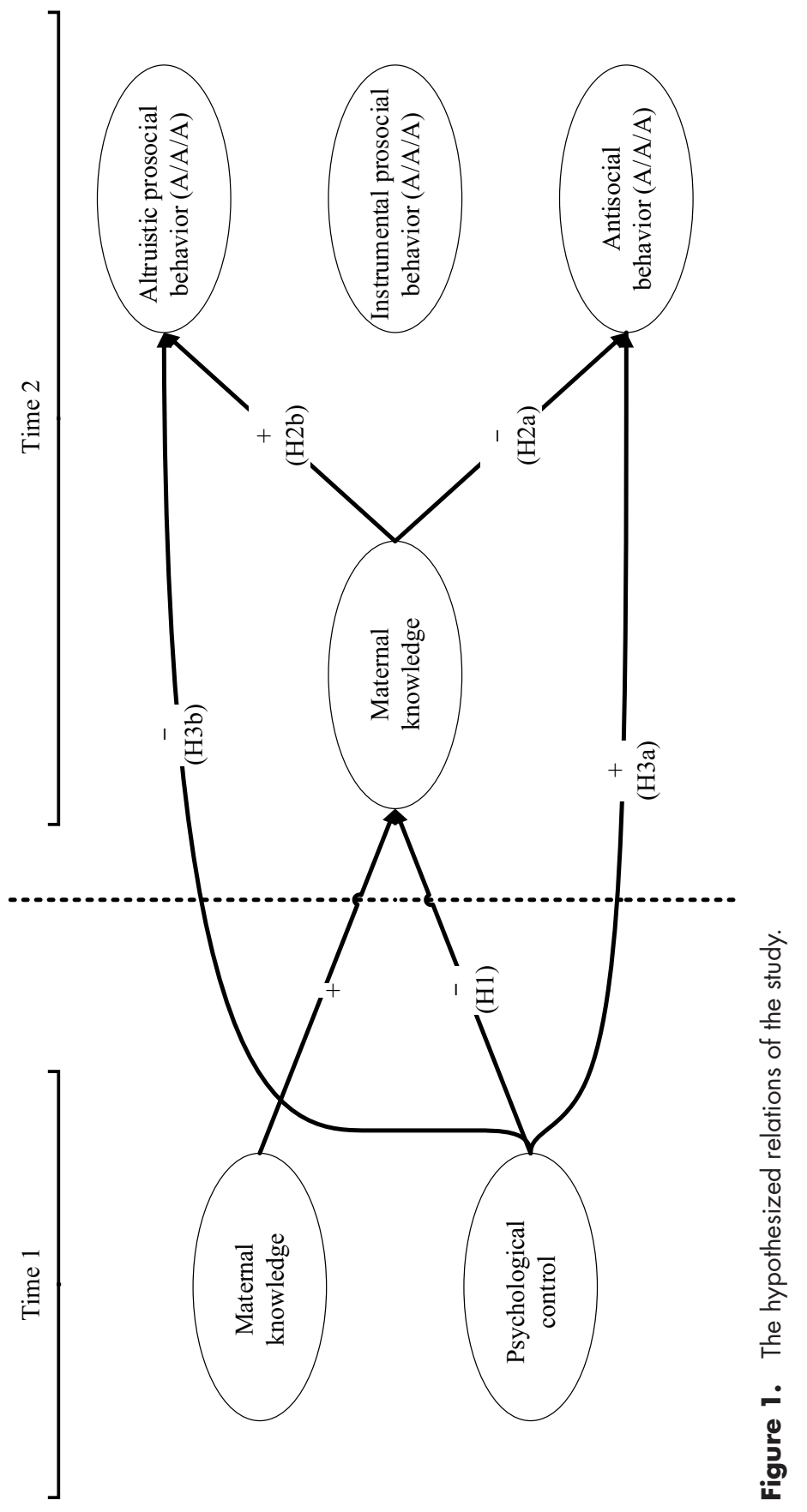


Further, and in line with prior findings showing the maladaptive effects of psychological control on adolescents' social functioning (e.g., Galambos et al., 2003; Hoeve et al., 2009; Kuppens et al., 2009), we expected psychological control to positively predict aggressive behavior (Hypothesis 3a). In contrast, we hypothesized that psychological control would negatively predict altruistic prosocial behavior (Hypothesis 3b), whereas we expected no relation to instrumental prosocial behavior. We also hypothesized that maternal knowledge would mediate, at least partially, the relation of psychological control to altruistic prosocial (Hypothesis 4a) and aggressive behavior (Hypothesis 4b).

When testing our hypotheses, we considered adolescents' gender and age and mothers' education level. We expected, in line with past evidence (e.g., Romano, Tremblay, Boulerice, \& Swisher, 2005), that boys would report higher aggressive and lower prosocial behavior than girls. We made no concrete hypothesis regarding the relation of mother's education level to psychological control, or maternal knowledge, as no consistent links have been reported in the literature (e.g., Bean, Bush, McKenry, \& Wilson, 2003; Smetana \& Daddis, 2002).

\section{Method}

\section{Participants and Procedure}

Two hundred and twenty-nine adolescents $\left(M_{\text {age }}=11.89\right.$ years, $S D=0.32$, $47.0 \%$ boys) and their mothers were recruited from three different cities in Turkey (Istanbul, Ankara, and Bolu). The attrition rate from Time 1 (T1) to Time 2 (T2) was $3.0 \%$. Attrition analysis suggested that participants in our retained sample did not differ in substantial ways from the participants for whom we had missing values-Little's MCAR (missing completely at random) test, $\chi^{2}(75)=72.12, p=.57$. Most of the participants came from families with middle-class socioeconomic status. Regarding mothers' education, $111(48.3 \%)$ of them had an elementary-school diploma or less, whereas $17(7.4 \%)$ had a middle-school diploma, 72 (31.3\%) had a highschool diploma, and 30 (13.0\%) had a 4-year university degree or more.

Having obtained principals' permission, we sent an invitation letter to the mothers through their children in which we informed them about the scope of our study, assured them about its confidentiality, and then asked them to consent to their child, and their own, participation. The questionnaires were sent to those who agreed to participate and were returned through their child. The questionnaires for the adolescents were administered by two researchers and completed at schools during a regular class 
hour. In T1, we assessed (mother-rated and adolescent-rated) maternal knowledge and psychological control; 1 year later, in T2, we assessed (mother-rated and adolescent-rated) maternal knowledge of adolescents' whereabouts and friendships. as well as adolescents' reports regarding their own altruistic prosocial, instrumental prosocial, and aggressive behavior.

\section{Measures}

Psychological control (Tl adolescent and mother reports). Participants filled out 16 items from two scales developed by Barber and colleagues (Barber, 1996; Barber et al., 2012) — that is, the Psychological Control Scale (e.g., "My mother is always trying to change how I feel or think about things") and the Psychological Control-Disrespect Scale (e.g., "My mother is a person who embarrasses me in public"). The internal consistency (Cronbach's alpha) of the 16-item, 4-point Likert-type scale $(1=$ never and $4=$ always $)$ was $\alpha=.79$ for adolescent reports and $\alpha=.89$ for mother reports.

Maternal knowledge (T1 and T2 adolescent and mother reports). A scale developed by Kerr and Stattin (2000) was used to assess the degree to which the mother knows about her adolescents' whereabouts and friendships. Children answered eight questions in a 5-point Likert-type scale $(1=$ never knows and $5=$ always knows $)$ about their mothers' knowledge (e.g., "My mother knows what I do during my free time"). Mothers answered to the same 5-point Likert-type questions with some minor changes in wording, where necessary $(1=$ never know and $5=$ always know $)$. Cronbach alphas across the two informants and the two assessment waves were ranging .79-.84.

Prosocial and aggressive behaviors (T2 adolescent report). To measure altruistic prosocial, instrumental prosocial, and aggressive behavior, we relied on the questionnaire developed by Boxer et al. (2004) in which adolescents indicated the response choice that "best described them as a person" on a 6-point response scale ranging from 1 (definitely not like me) to 6 (definitely like me). The scale consisted of five five-item subscales:

1. Altruism that taps into behaviors where one acts voluntarily without expectation of personal gain (e.g., "I often help people without being asked," $\alpha=.73$ ).

2. Reactive prosocial behavior that reflects a positive affective response (e.g., "When someone puts me in a good mood, I will often help them if they ask," $\alpha=.75$ ).

3. Proactive prosocial behavior that refers to instrumental, goaldirected responses (e.g., "I often help people to get what I want," $\alpha=.84)$. 
4. Proactive aggressive behavior that taps into instrumental, goaldirected responses (e.g., "I often hit people to get what I want," $\alpha=.80)$.

5. Reactive aggressive behavior that assesses negative affective response to an individual (e.g., "When someone makes me angry or upset, I will often hit them for it," $\alpha=.84$ ).

Preliminary analyses showed, in line with Boxer et al. (2004), that altruistic prosocial behavior and reactive prosocial behavior were positively and moderately to highly correlated $(r=.63, p<.01)$; they both were negatively correlated with the two forms of aggressive behavior (range of $r s=-.14$ to -.27 , $p s<.01)$, which were positively intercorrelated $(r=.71, p<.01)$. In contrast, proactive (i.e., instrumental) prosocial behavior was only moderately correlated with altruistic $(r=.32, p<.02)$ and reactive prosocial behavior $(r=.30$, $p<.01)$, whereas it was positively related to reactive aggressive behavior $(r$ $=.16, p<.01)$ and not related to proactive aggressive $(r=.09, p=.09)$. This pattern of associations supported the argument that instrumental prosocial behavior was orthogonal from altruistic, pure prosocial behaviors and led us to consider three main components: altruistic prosocial behavior (i.e., the combination of altruistic and reactive prosocial behavior), instrumental prosocial behavior, and aggressive behavior (i.e., the combination of proactive aggressive behavior and reactive aggressive behavior).

\section{Results}

\section{Preliminary Analyses}

Descriptive statistics and bivariate correlations are shown in Table 1. As can be seen, girls reported higher maternal knowledge and less maternal psychological control and instrumental prosocial and aggressive behavior than did boys. In addition, adolescents' age was negatively related to T2 mother-reported knowledge while mothers' education level was positively related to T2 adolescent-reported maternal knowledge. Mother-reported psychological control was positively related to adolescent-reported psychological control and aggressive behavior and negatively to mother-reported and adolescent-reported T1 and T2 maternal knowledge. A similar pattern was found for adolescent-reported psychological control, which also related negatively to altruistic prosocial behavior. T1 and T2 mother-reported and adolescent-reported maternal knowledge were positively intercorrelated, and they all related positively to altruistic prosocial and negatively to aggressive behavior. 


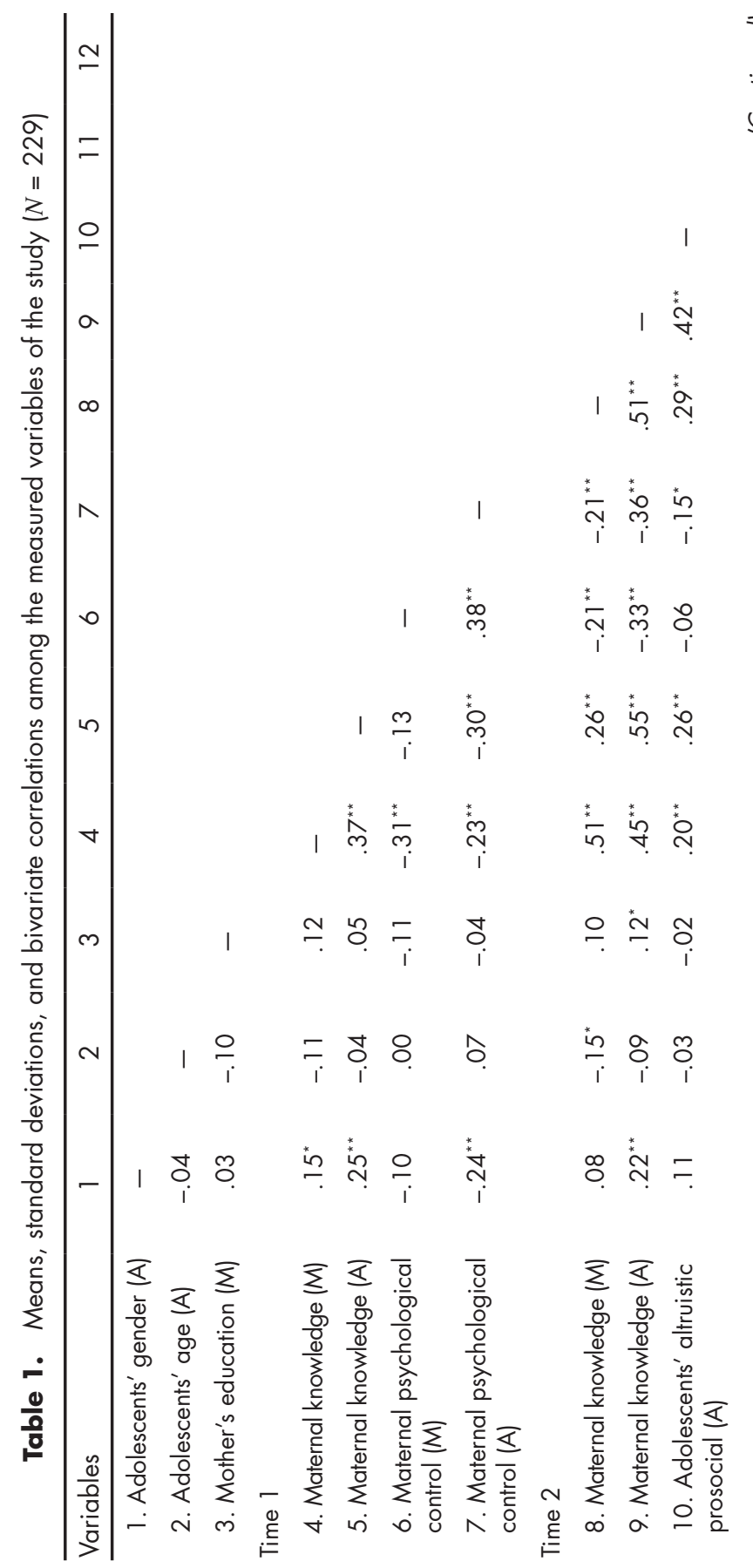




$$
\lfloor
$$




\section{Main Analyses}

To test our hypotheses, we tested three structural equation models in which maternal psychological control predicted maternal knowledge 1 year later that in turn was associated with adolescent-reported aggressive, altruistic prosocial and instrumental prosocial behavior. To examine whether the patterns of the hypothesized associations would hold irrespective of the informants, we tested three separate models, one with adolescent-reported maternal psychological control and maternal knowledge (the adolescent model), one with mother-reported psychological control and knowledge (the mother model), and a third one with mother-reported psychological control predicting adolescent-reported maternal knowledge (the crossinformant mother-adolescent model).

All models were tested with the R package lavaan (Rosseel, 2012). In all models, a latent factor for psychological control was defined by eight parcels (four parcels, each averaging two items assessing psychological control, and four parcels, each averaging two items assessing psychological control-disrespect). Also, a latent factor for maternal knowledge was defined in both waves by four parcels, each aggregating two items from the respective scale. Altruistic prosocial higher-order latent factor was defined by altruistic and reactive prosocial latent factors (each defined by two parcels-the one averaging two items and the other the remaining three items from the respective scale). Instrumental prosocial behavior was also defined by a three-item parcel and a two-item parcel indicator. The latent factor for aggressive behavior was defined by four parcels - a pair that consisted of a two-item parcel and a three-item parcel that corresponded to the five items assessing proactive aggressive behavior, and another pair that also consisted of a two-item parcel and a three-item parcel and that corresponded to the five items assessing reactive aggressive behavior. To properly identify all the models, we imposed an additional constraint of equality loadings to all the latent factors that were defined by two indicators (Kline, 2011). Adolescents' gender and age, as well as mother's education, were included as covariates in all the three models. Only the statistically significant paths among the latent factors were retained in the final models. By fixing the statistically nonsignificant paths, we tested the fit of each of the models more conservatively.

The adolescent model. The adolescent model, shown in Figure 2 (first set of coefficients), yielded acceptable fit per the Satorra-Bentler chi-square statistic $S-B \chi^{2}(354, N=261)=448.02, p<.01$, comparative fit index (CFI) $=.965$, standardized root mean square residual $(\mathrm{SRMR})=.048$, and root mean square error of approximation $($ RMSEA $)=.032(90 \%$ confidence interval $[\mathrm{CI}] .022-.040)$. As can be seen in Figure 2, T1 maternal psychological 


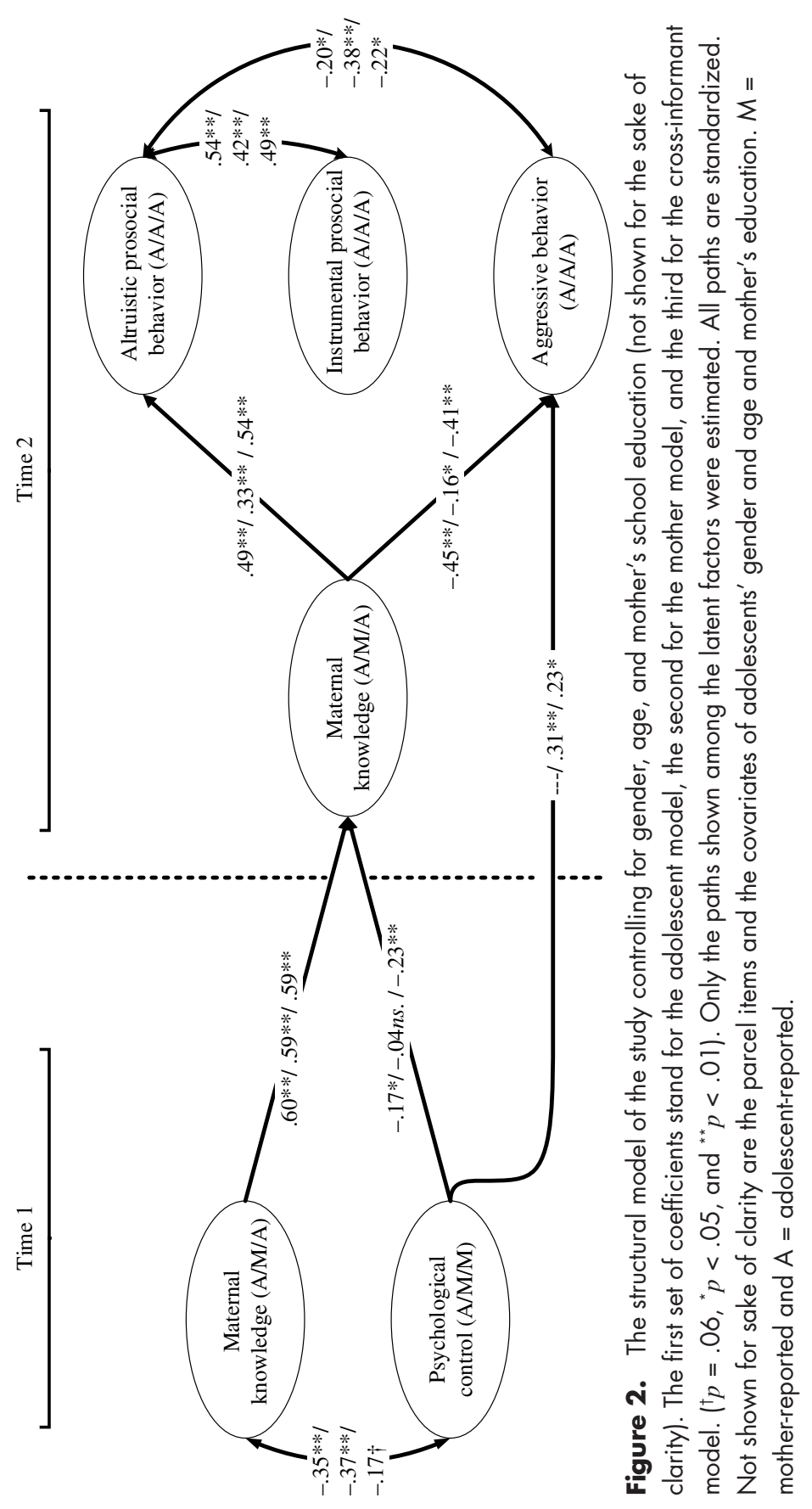


control as perceived by the adolescents was related negatively to maternal knowledge at T1. More important, after controlling for T1 maternal knowledge, we found T1 maternal psychological control to negatively predict adolescent-reported maternal knowledge 1 year later (providing support for Hypothesis 1), which in turn was associated negatively with aggressive behavior (Hypothesis 2a) and positively with altruistic prosocial behavior (Hypothesis 2b), whereas it was unrelated to instrumental prosocial behavior (Hypothesis 2c). Although we failed to find support for Hypotheses 3a and $\mathrm{b}$ because T1 maternal psychological control did not directly predict either altruistic behavior or aggressive behavior, a test of indirect effects showed that T1-perceived psychological control was indirectly related (negatively) to T2 altruistic prosocial behavior $(b=-0.07, S E=0.03, p=.025, \beta=-.08$ ) and (positively) to T2 aggressive behavior ( $b=0.06, S E=0.03, p=.044, \beta$ $=.08)$ through T2 maternal knowledge. These results supported Hypotheses 4a and b, respectively. Among the covariates (i.e., mother's education level and adolescents' gender and age, which are not shown in Figure 2 for reasons of parsimony), only adolescents' gender was found to relate negatively to T1 maternal psychological control $(\beta=-.28, p<.01)$ and T2 instrumental prosocial behavior $(\beta=-.16, p=.015)$. These findings suggest that girls as compared to boys perceived their mothers as being less psychologically controlling but reported less instrumental prosocial behavior.

The mother model. While the fit of the mother model was generally adequate, it yielded a somewhat poorer fit as compared to the adolescent model, $S$ $B \chi^{2}(354, N=213)=498.18, p<.01, \mathrm{CFI}=.915$, SRMR $=.067$, and RMSEA $=.044(90 \%$ [CI $.035-.052)$. An inspection of the modification indices suggested an addition of a direct path from psychological control to aggressive behavior, which supported Hypothesis 3a. The revised model—see the second set of coefficients in Figure 2-yielded a somewhat better fit, $S-B \chi^{2}(353, N=$ $213)=485.45, p<.01, \mathrm{CFI}=.922, \mathrm{SRMR}=.056$, and RMSEA $=.042(90 \%$ [CI] .033-.050). As can be noticed, the patterns of associations that were found for the adolescent model were largely reproduced in the mother model, except for one important difference: The path between T1 mother-reported psychological control and T2 mother-reported maternal knowledge was statistically nonsignificant. This finding failed to support Hypothesis 1 as it showed that the relation between psychological control and maternal knowledge did not hold when the mothers were the informants. Interestingly, the relation between T2 mother-reported maternal knowledge and T2 adolescent-reported aggressive behavior was marginally significant. Also, the lack of relation between T1 psychological control and T2 maternal knowledge precluded the possibility of finding support for Hypotheses $4 \mathrm{a}$ and $\mathrm{b}$ (i.e., that psychological control would indirectly relate to altruistic prosocial and aggressive behavior). However, the 
lack of indirect effects from T1 psychological control to T2 aggressive behavior was partly due to the two constructs being directly associated with each other (see Figure 2). Further, the pattern of the relations among the covariates of mother's education level and adolescents' age and gender (not shown in Figure 2) were similar to that of the adolescent model.

The cross-informant mother-adolescent model. This model yielded the following fit: $S-B \chi^{2}(353, N=226)=481.71, p<.01$, CFI $=.937$, SRMR $=.055$, RMSEA $=.040(90 \%[C I] .031-.048)$. As can be seen in Figure 2 (the third set of coefficients), the relation of mother-reported maternal knowledge was positive (albeit marginally) for mother-reported psychological control at T1. Also, aligned with Hypothesis 1, T1 mother-reported psychological control negatively predicted $\mathrm{T} 2$ adolescent-reported maternal knowledge, which in turn, in support of Hypotheses 2a-c, was negatively associated with aggressive behavior, positively associated with altruistic prosocial behavior, and not related to instrumental prosocial behavior. Similar to the mother model, aggressive behavior was also directly predicted by mother-reported psychological control (providing support for Hypothesis 3a). Irrespective of this direct path, a test of indirect effects further showed, similar to the adolescent model and in support of Hypotheses 4a and b, that T1-perceived psychological control was indirectly related negatively to T2 altruistic prosocial behavior $(b=-0.27, S E=0.10, p<.01, \beta=-.12)$ and positively to T2 aggressive behavior $(b=0.19, S E=0.08, p=.020, \beta=.10$ ) by means of T2 maternal knowledge. Finally, the pattern of the relations among the covariates of mother's education level and adolescents' age and gender were similar to the adolescent model and the mother model. ${ }^{1}$

\section{Discussion}

In this 1-year prospective study, we investigated to what extent maternal psychological control predicts maternal knowledge of her adolescents' whereabouts and friendships and whether this knowledge, in turn, relates to adolescents' altruistic prosocial, instrumental prosocial, and aggressive behavior. To examine this pattern of associations, we relied on both

1. We also tested a cross-informant adolescent-mother model, with adolescent-reported maternal knowledge predicting mother-reported psychological control. That model yielded also acceptable fit: $S-B \chi^{2}(354, N=212)=459.03, p<.01, \mathrm{CFI}=.946, \mathrm{SRMR}=.057$, and RMSEA $=.037(90 \%$ [CI] .027-.046). Similar to the mother model, yet in the expected direction, T1 adolescent-reported psychological control failed to negatively predict T2 mother-reported maternal knowledge $(\beta=-.11, p=.15, n s)$. As in the mother model also, mother-reported maternal knowledge related positively to adolescent-reported altruistic prosocial behavior $(\beta=.33, p<.01)$ and negatively to aggressive behavior $(\beta=-.25, p=.020)$. 
mothers' and adolescents' reports while controlling for baseline maternal knowledge. Building on prior research, and in support of most of our hypotheses, we found mother-reported or adolescent-reported psychological control to inversely predict adolescent-reported maternal knowledge, which, in turn related negatively to aggressive behavior and positively to altruistic prosocial behavior (but not to instrumental prosocial behavior). Interestingly, we found no relation between psychological control and maternal knowledge when the informant of maternal knowledge was the mother. These findings extend our knowledge in two important ways and are discussed in the following sections.

\section{Psychological Control and Decreased Maternal Knowledge}

Is maternal psychological control associated, among other drawbacks, with limited knowledge regarding the mother's offspring's whereabouts and friendships? According to what the adolescents admit that their parents know about their own whereabouts, friendships, and activities, our findings indeed suggest a negative relation between psychologically controlling practices and such knowledge. Irrespective of whether psychological control was assessed through mothers or adolescents, a negative relation emerged between maternal psychological control and adolescent-reported (but not mother-reported) maternal knowledge. So, the more a mother admitted that she intruded and disrespected her child's private space (or the more she was perceived as doing so by her child), the less her child reported that the mother knew about his or her whereabouts and friendships. Because psychological control threatens adolescents' need for autonomy (Soenens \& Vansteenkiste, 2010), it seems likely that adolescents will react against pressuring parental attempts to solicit information (Van Petegem et al., 2015). Such reactance may manifest as withholding information or even as concealment and lying, all of which result in lowered parental knowledge (Smetana, 2008).

Our findings are consistent with a number of previous studies, which were however limited by a reliance on the same informants to assess both constructs (Soenens et al., 2006). In this regard, we should note that the negative relation of $\mathrm{T} 1$ maternal psychological control to $\mathrm{T} 2$ maternal knowledge was annulled when we asked the very same mothers about how much psychological control they exert over their child and how many things they know about their child's whereabouts, activities, and friendships (after we had controlled for baseline maternal knowledge). The different pattern of relations resembles somehow the findings reported by Soenens et al. (2006), who found the relation between psychological control and maternal 
knowledge to be somewhat weaker when the informants were the mothers than the adolescents. Does this mean that mothers tend to dissociate the two issues-probably, because they, on average, underestimate the psychological control they exert over their children while overestimating the maternal knowledge they gain from them? Inspection of the means in our data could suggest so, as the mothers tended to score higher in maternal knowledge and lower in psychological control than adolescents. These findings are consistent with a recent meta-analysis demonstrating that parents provide a more positive picture of their parenting qualities than do adolescents (Korelitz \& Garber, 2016). One possibility is that social desirability may affect parental reports of parenting more strongly than adolescent reports. Another possibility is that parents are more inclined than adolescents to respond in terms of how they would like to raise their children and not so much in terms of what they actually do. These problems are particularly likely to be at play with a construct such as parental knowledge (a resource highly valued by most parents), resulting in relatively less valid assessment when relying on parent reports. Certainly, the issue of the actual relation between maternal knowledge and psychological control depending on who the informant proves to be is an interesting issue that deserves further examination. Our results indicate that the relation between maternal knowledge and psychological control is negative when we asked adolescents. More important, we got the same negative relation when we relied on different informants - that is, when we asked the mothers about their use of psychological control and the adolescents about how many things their mothers know about their activities.

Overall, our findings are in line with findings from most previous studies and suggest that maternal psychological control relates to diminished maternal knowledge about children's whereabouts and friendships, possibly because adolescents are less willing to be open about their activities when parenting style is non-pressuring or autonomy-suppressing (Fletcher et al., 2004; Hawk et al., 2013). These findings do not mean that parents should distance themselves from their adolescents to foster knowledge. Most likely, parental knowledge increases when parents are actively involved, yet in a structured and autonomy-supportive way (Mauras, Grolnick, \& Friendly, 2013). When parents provide clear guidelines for appropriate behavior (structure) and at the same time display an interest in the adolescent's perspective about these guidelines and allow some freedom in the way expectations are met (autonomy support), adolescents are more likely to let their parents know about their own personal activities, friendships, and whereabouts because they will feel more free to discuss matters with their parents in an open and honest fashion (Bureau \& Mageau, 
2014; Roth, Ron, \& Benita, 2009; Wuyts, Soenens, Vansteenkiste, \& Van Petegem, 2018).

\section{Maternal Knowledge and Social Functioning}

In our study, we examined not only the relation between maternal knowledge and aggressive behavior but also its relation to prosocial behavior. By distinguishing prosocial behavior as a true, altruistic prosocial type and a more strategic, instrumental one (Batson et al., 2005), we could examine whether maternal knowledge would be related differentially to the two types of prosocial behavior, thereby gaining more insight in the dynamics involved in maternal knowledge. As expected, we found that maternal knowledge was not only related negatively to aggressive behavior but also positively to altruistic prosocial behavior. There was no association with instrumental prosocial behavior. Taken together, the link between adolescent-reported maternal knowledge and aggressive behaviors, along with the pattern of associations linking maternal knowledge with adolescents' social behaviors, implies that maternal knowledge might serve as a basis for constructive mother-adolescent dialogue not only about the prevention of problem behaviors but also about prosocial values and behaviors.

Importantly, maternal knowledge also played a significant intervening role in the associations between psychologically controlling parenting and adolescent behavior, suggesting that low maternal knowledge is (part of) the process through which psychologically controlling parenting increases the risk for problem behaviors and decreases the likelihood of adolescents engaging in prosocial behavior. An important avenue for future research is to replicate and extend this finding. Possibly, maternal knowledge is, in itself, a manifestation of a more fundamental intervening process linking psychologically controlling parenting to dysfunctional adolescent behavior. For instance, theory and research suggest that psychologically controlling parenting hampers adolescents' internalization of parental values and guidelines for adaptive behavior (Grusec \& Goodnow, 1994; Vansteenkiste, Soenens, Van Petegem, \& Duriez, 2014) and even increases the odds that adolescents bluntly defy parental authority and values (Van Petegem et al., 2015). Perhaps the low levels of maternal knowledge associated with psychologically controlling parenting observed in the current study reflect a lack of internalization of parental values and even defiance against parental authority. When adolescents dismiss parental expectations for proper behavior, they are likely to withhold information from their parents, such that parents are ill-informed. Low maternal knowledge may then be a surface manifestation of deeper problems associated with parental 
psychological control that may include oppositional defiance and failed internalization of parental values, with the latter processes eventually driving the associations between psychologically controlling parenting and adolescent problem behavior. Thus, future research is needed to examine additional mediators of associations between parenting, parental knowledge, and adolescent behavior, including internalization and defiance, but also the overall quality of parent-child relationships and child's attachment to the parents.

\section{Limitations}

Our study has several limitations. First, despite our prospective design and our use of mothers' and adolescents' reports to examine our hypotheses, we cannot claim causality in the relations found. It is likely that mothers who realize that they are inadequately aware of their children whereabouts and friendships behave in a more psychologically controlling way towards their children. Psychological control could thus be considered as a means to pressure the child to disclose personal information in response to limited maternal knowledge. However, this alternative possibility was less likely because, although the bivariate correlations between T1 mother-reported psychological control and T2 mother-reported maternal knowledge was negative, it was null when we controlled for T1 mother-reported maternal knowledge and adolescents' prosocial behavior towards parents. Further, it should be underscored that our sample consisted of Turkish early adolescents. We note this issue because in Turkey early adolescents spend much less time outdoors so mothers are expected to be acquainted with their children's behaviors. In any case, we could not rule out that mothers may behave in a psychologically controlling fashion if they detect that their children misbehave or that the children do not act in an altruistic prosocial way. Most likely, a bidirectional process operates, but future studies with experimental designs or longitudinal studies with cross-lagged analyses can more validly examine these reciprocal dynamics. In addition, it should be noted that we relied exclusively on adolescents to assess their prosocial and aggressive behavior while not considering fathers, although prior studies suggest that structural associations are similar for mothers and fathers (e.g., Soenens et al., 2006). Future studies need to include more objective behavioral measures or triangulate adolescents' reports with ratings coming from their mothers, fathers, teachers, and peers. Another limitation concerns the generalizability of our findings to other cultures, although similar processes have been observed among older adolescents in other countries and cultures. Certainly, more crosscultural research is needed. 


\section{Conclusion}

Maternal knowledge of adolescents' whereabouts and friendships seems to mediate the relation of psychological control to adolescents' prosocial and aggressive behavior. Considering the importance of parental knowledge for adolescents' social development in general, we need more (preferably longitudinal) research identifying parental practices that facilitate parental knowledge and the likely mechanisms that may explain the link between parental knowledge and prosocial behavior.

\section{References}

Ary, D. V., Duncan, T. E., Biglan, A., Metzler, C. W., Noell, J. W., \& Smolkowski, K. (1999). Development of adolescent problem behavior. Journal of Abnormal Child Psychology, 27, 141-150. doi:10.1023/a:1021963531607

Barber, B. K. (1996). Parental psychological control: Revisiting a neglected construct. Child Development, 67, 3296-3319. doi:10.1111/j.1467-8624.1996. tb01915.x

Barber, B. K., Stolz, H. E., Olsen, J. A., Collins, W. A., \& Burchinal, M. (2005). Parental support, psychological control, and behavioral control: Assessing relevance across time, culture, and method. Monographs of the Society for Research in Child Development, 70, 1-147. doi:10.2307/3701442

Barber, B. K., Xia, M., Olsen, J. A., McNeely, C. A., \& Bose, K. (2012). Feeling disrespected by parents: Refining the measurement and understanding of psychological control. Journal of Adolescence, 35, 273-287. doi:10.1016/j. adolescence.2011.10.010

Batson, C. D., Ahmad, N., Powell, A. A., \& Stocks, E. L. (2005). Prosocial motivation. In J. Shah \& W. Gardner (Eds.), Handbook of motivation science (pp. 135-149). New York: Guilford Press.

Batson, C. D., \& Shaw, L. L. (1991). Evidence for altruism: Toward a pluralism of prosocial motives. Psychological Inquiry, 2, 107-122. doi:10.2307/1449242

Bean, R. A., Bush, K. R., McKenry, P. C., \& Wilson, S. M. (2003). The impact of parental support, behavioral control, and psychological control on the academic achievement and self-esteem of African American and European American adolescents. Journal of Adolescent Research, 18, 523-541. doi:10.1177/0743558403255070

Boxer, P., Tisak, M. S., \& Goldstein, S. E. (2004). Is it bad to be good? An exploration of aggressive and prosocial behavior subtypes in adolescence. Journal of Youth and Adolescence, 33, 91-100. doi:10.1023/B:JOYO.0000013421.02015.ef

Bureau, J. S., \& Mageau, G. A. (2014). Parental autonomy support and honesty: The mediating role of identification with the honesty value and perceived costs and benefits of honesty. Journal of Adolescence, 37, 225-236. doi:10.1016/j. adolescence.2013.12.007 
Carlo, G., Mestre, M. V., McGinley, M. M., Tur-Porcar, A., Samper, P., \& Opal, D. (2014). The protective role of prosocial behaviors on antisocial behaviors: The mediating effects of deviant peer affiliation. Journal of Adolescence, 37, 359-366. doi:10.1016/j.adolescence.2014.02.009

Crouter, A. C., \& Head, M. R. (2002). Parental monitoring and knowledge of children. In M. H. Bornstein (Ed.), Handbook of parenting: Vol. 3. Being and becoming a parent (2nd ed., pp. 461-483). Mahwah, NJ: Erlbaum.

Culotta, C. M., \& Goldstein, S. E. (2008). Adolescents' aggressive and prosocial behavior: Associations with jealousy and social anxiety. Journal of Genetic Psychology, 169, 21-33. doi:10.3200/gntp.169.1.21-33

Dishion, T., \& McMahon, R. (1998). Parental monitoring and the prevention of child and adolescent problem behavior: A conceptual and empirical formulation. Clinical Child and Family Psychology Review, 1, 61-75. doi:10.1023/A:1021800432380

Elgar, F. J., Mills, R. S. L., McGrath, P. J., Waschbusch, D. A., \& Brownridge, D. A. (2007). Maternal and paternal depressive symptoms and child maladjustment: The mediating role of parental behavior. Journal of Abnormal Child Psychology, 35, 943-955. doi:10.1007/s10802-007-9145-0

Fletcher, A. C., Steinberg, L., \& Williams-Wheeler, M. (2004). Parental influences on adolescent problem behavior: Revisiting Stattin and Kerr. Child Development, 75, 781-796. doi:10.1111/j.1467-8624.2004.00706.x

Gaertner, A. E., Fite, P. J., \& Colder, C. R. (2010). Parenting and friendship quality as predictors of internalizing and externalizing symptoms in early adolescence. Journal of Child and Family Studies, 19, 101-108. doi:10.1007/ s10826-009-9289-3

Galambos, N. L., Barker, E. T., \& Almeida, D. M. (2003). Parents do matter: Trajectories of change in externalizing and internalizing problems in early adolescence. Child Development, 74, 578-594. doi:10.1111/1467-8624.7402017

Grusec, J. E., \& Goodnow, J. J. (1994). Impact of parental discipline methods on the child's internalization of values: A reconceptualization of current points of view. Developmental Psychology, 30, 4-19. doi:10.1037/0012-1649.30.1.4

Hawk, S. T., Keijsers, L., Frijns, T., Hale III, W. W., Branje, S., \& Meeus, W. (2013). "I still haven't found what I'm looking for": Parental privacy invasion predicts reduced parental knowledge. Developmental Psychology, 49, 1286-1298. doi:10.1037/a0029484

Hoeve, M., Dubas, J. S., Eichelsheim, V. I., van der Laan, P. H., Smeenk, W., \& Gerris, J. R. M. (2009). The relationship between parenting and delinquency: A meta-analysis. Journal of Abnormal Psychology, 37, 749-775. doi:10.1007/ s10802-009-9310-8

Horton, R. S., \& Tritch, T. (2014). Clarifying the links between grandiose narcissism and parenting. Journal of Psychology, 148, 133-143. doi:10.1080/0022 3980.2012 .752337 
Kerr, M., \& Stattin, H. (2000). What parents know, how they know it, and several forms of adolescent adjustment: Further support for a reinterpretation of monitoring. Developmental Psychology, 36, 366-380. doi:10.1037/0012-1649.36.3.366

Kline, R. B. (2011). Principles and practice of structural equation modeling (3rd ed.). New York: Guilford Press.

Korelitz, K. E., \& Garber, J. (2016). Congruence of parents' and children's perceptions of parenting: A meta-analysis. Journal of Youth and Adolescence, 45, 1973-1995. doi:10.1007/s10964-016-0524-0

Kuppens, S., Grietens, H., Onghena, P., \& Michiels, D. (2009). Relations between parental psychological control and childhood relational aggression: Reciprocal in nature? Journal of Clinical Child \& Adolescent Psychology, 38, 117-131. doi:10.1080/15374410802575354

Laird, R. D., Pettit, G. S., Dodge, K. A., \& Bates, J. E. (2003). Change in parents' monitoring knowledge: Links with parenting, relationship quality, adolescent beliefs, and antisocial behavior. Social Development, 12, 401-419. doi:10.1111/1467-9507.00240

Lansford, J. E., Laird, R. D., Pettit, G. S., Bates, J. E., \& Dodge, K. A. (2014). Mothers' and fathers' autonomy-relevant parenting: Longitudinal links with adolescents' externalizing and internalizing behavior. Journal of Youth and Adolescence, 43, 1877-1889. doi:10.1007/s10964-013-0079-2

Mabbe, E., Soenens, B., Vansteenkiste, M., \& Van Leeuwen, K. (2016). Do personality traits moderate relations between psychologically controlling parenting and problem behavior in adolescents? Journal of Personality, 84, 381-392. doi:10.1111/jopy.12166

Mauras, C. P., Grolnick, W. S., \& Friendly, R. W. (2013). Time for "the talk" . . . now what? Autonomy support and structure in mother-daughter conversations about sex. Journal of Early Adolescence, 33, 458-481. doi:10.1177/0272431612449385

McGinley, M., \& Carlo, G. (2007). Two sides of the same coin? The relations between prosocial and physically aggressive behaviors. Journal of Youth and Adolescence, 36, 337-349. doi:10.1007/s10964-006-9095-9

Pettit, G. S., Laird, R. D., Dodge, K. A., Bates, J. E., \& Criss, M. M. (2001). Antecedents and behavior-problem outcomes of parental monitoring and psychological control in early adolescence. Child Development, 72, 583-598. doi:10.1111/1467-8624.00298

Romano, E., Tremblay, R., Boulerice, B., \& Swisher, R. (2005). Multilevel correlates of childhood physical aggression and prosocial behavior. Journal of Abnormal Child Psychology, 33, 565-578. doi:10.1007/s10802-005-6738-3

Rosseel, Y. (2012). lavaan: An R package for structural equation modeling. Journal of Statistical Software, 48, 1-36. doi:10.18637/jss.v048.i02 
Roth, G., Ron, T., \& Benita, M. (2009). Mothers' parenting practices and adolescents' learning from their mistakes in class: The mediating role of adolescent's self-disclosure. Learning and Instruction, 19, 506-512. doi:10.1016/j. learninstruc.2008.10.001

Smetana, J. G. (2008). "It's 10 o'clock: Do you know where your children are?" Recent advances in understanding parental monitoring and adolescents' information management. Child Development Perspectives, 2, 19-25. doi:10.1111/j.1750-8606.2008.00036.x

Smetana, J. G., \& Daddis, C. (2002). Domain-specific antecedents of parental psychological control and monitoring: The role of parenting beliefs and practices. Child Development, 73, 563-580. doi:10.1111/1467-8624.00424

Smetana, J. G., Metzger, A., Gettman, D. C., \& Campione-Barr, N. (2006). Disclosure and secrecy in adolescent-parent relationships. Child Development, 77, 201-217. doi:10.1111/j.1467-8624.2006.00865.x

Smetana, J. G., \& Rote, W. M. (2015). What do mothers want to know about teens' activities? Levels, trajectories, and correlates. Journal of Adolescence, 38, 5-15. doi:10.1016/j.adolescence.2014.10.006

Soenens, B., \& Vansteenkiste, M. (2010). A theoretical upgrade of the concept of parental psychological control: Proposing new insights on the basis of self-determination theory. Developmental Review, 30, 74-99. doi:10.1016/j.dr.2009.11.001

Soenens, B., Vansteenkiste, M., Goossens, L., Duriez, B., \& Niemiec, C. P. (2008). The intervening role of relational aggression between psychological control and friendship quality. Social Development, 17, 661-681. doi:10.1111/j.1467-9507.2007.00454.x

Soenens, B., Vansteenkiste, M., Luyckx, K., \& Goossens, L. (2006). Parenting and adolescent problem behavior: An integrated model with adolescent self-disclosure and perceived parental knowledge as intervening variables. Developmental Psychology, 42, 305-318. doi:10.1073/0012-1649.42.2.305

Stattin, H., \& Kerr, M. (2000). Parental monitoring: A reinterpretation. Child Development, 71, 1072-1085. doi:10.1111/1467-8624.00210

Tilton-Weaver, L., Kerr, M., Pakalniskeine, V., Tokic, A., Salihovic, S., \& Stattin, H. (2010). Open up or close down: How do parental reactions affect youth information management? Journal of Adolescence, 33, 333-346. doi:10.1016/j. adolescence.2009.07.011

Van Petegem, S., Soenens, B., Vansteenkiste, M., \& Beyers, W. (2015). Rebels with a cause? Adolescent defiance from the perspective of reactance theory and self-determination theory. Child Development, 86, 903-918. doi:10.1111/ cdev. 12355

Vansteenkiste, M., Soenens, B., Van Petegem, S., \& Duriez, B. (2014). Longitudinal associations between adolescent perceived degree and style of parental prohibition and internalization and defiance. Developmental Psychology, 50, 229236. doi:10.1037/a0032972 
Veronneau, M. H., \& Dishion, T. J. (2010). Predicting change in early adolescent problem behavior in the middle school years: A mesosystemic perspective on parenting and peer experiences. Journal of Abnormal Child Psychology, 38, 1125-1137. doi:10.1007/s10802-010-9431-0

Weinstein, N., DeHaan, C. R., \& Ryan, R. M. (2010). Attributing autonomous versus introjected motivation to helpers and the recipient experience: Effects on gratitude, attitudes, and well-being. Motivation and Emotion, 34, 418-431. doi:10.1007/s11031-010-9183-8

Wuyts, D., Soenens, B., Vansteenkiste, M., \& Van Petegem, S. (2018). The role of observed maternal autonomy support, reciprocity, and need satisfaction in adolescent discourse about friends. Journal of Adolescence, 65, 141-154. doi:10.1016/j.adolescence.2018.03.012 